\title{
Anthropometric Investigation of Head Measurements for Indian Adults
}

\author{
Parth SHAH ${ }^{1}$, Yan LUXIMON ${ }^{\star 1}$, Fang FU ${ }^{1}$, Vividh MAKWANA ${ }^{2}$ \\ ${ }^{1}$ School of Design, The Hong Kong Polytechnic University, Hong Kong; \\ ${ }^{2}$ Navneet Hi-Tech Hospital and Research Centre, Mumbai, India
}

DOI: $10.15221 / 18.114 \quad$ http://dx.doi.org/10.15221/18.114

\begin{abstract}
One of the primary purpose of head related products is to protect the head. To perform their function well, these products need to be in close contact with the head, so in order to ensure a good fit, the designers need accurate anthropometric data. Till date only a few studies have been conducted on Indian adult population to acquire their head shape data and hence there is a need of conducting such studies so as to help in customizing products for Indian population. In this paper authors presents a preliminary investigation of four anthropometric parameters namely head length, width, circumference and anterior height. Thirty male and thirty female adults participated in the study, in which their anthropometric measurements were acquired from 3D head models developed from Computed Tomography (CT) image data. The acquired data was further statistically analyzed to create an understanding of the head shape of Indian adults. The mean values of the acquired data showed the difference in sizes of males and female heads. The analysis also showed a significant correlation between head length and circumference for both male and female participants.
\end{abstract}

Keywords: Human head, anthropometry, Computed Tomography (CT), 3D modeling, 3D anthropometric measurements, India

\section{Introduction}

With the advancements in ergonomics, and consideration of a user centered approach product designers are focusing on user comforts and fit parameters [1] while designing daily product. Out of the wide range of products designed for head, many are primarily designed for the purpose of protection as head houses brain and several sensory organs. Some products are also designed for medical and aesthetic purposes [2]. All these products need to be in close fit with the head to effectively serve their purpose [3]. In order to ensure a good fit and optimal level of user comfort, the product designers need highly accurate anthropometric data.

With the use of traditional measurement techniques, it is difficult to acquire accurate anthropometric data due to the complex contour of the head [2]. In addition, acquisition of data using calipers, scales or tapes is time consuming and has low reliability [4-5]. However with the advancements in Computer aided design and modeling (CAD/CAM) technologies, it has become possible to develop accurate 3D digital human models, which can be used to acquire anthropometric measurements. Several techniques have been used to create 3D digital human models, including usage of medical imaging data like Computed Tomography (CT) [6-7]/ Magnetic Resonance Imaging (MRI) [8-9], usage of multiple images (Stereophotogrammetry technique) [10-11], and usage of advanced 3D scanners [12-13]. A detailed review on different existing head related 3D modeling techniques was presented in previous study by Shah and Luximon [14]. Accurate anthropometric data can be acquired easily from these 3D models using various 3D design software tools.

Various research groups around the world have created country, region or ethnic group specific 3D head shape databases [15-21] in past, which have been used for several applications. However, currently there are very few studies conducted on Indian population to generate a standard head shape database. Being the second most populated country in the world, India is a huge potential market for ergonomics designed products. Hence, it is essential to study head shape in order to help in designing and optimizing products for Indian population.

Hence, in the following paper, authors have tried to conduct a preliminary 3D anthropometric study to understand the head shape of Indian adults. In this study anthropometric measurements were acquired from the 3D models generated from CT images. The data acquired in this study can be helpful in understanding the relationship between factors like age, gender and different head parameters which could find applications not restricted to the field of product design, medicine and research.

“yan.luximon@polyu.edu.hk; +852 2766 5493; 


\section{Methodology}

\subsection{Participants}

Sixty Indian adult participants (30 males and 30 females) were invited to participate in this study. The participants were divided in five groups (19-29 years; 30-39 years; 40-49 years; 50-60 years; year 61 and above) based on their age. Every group had six participants each to avoid any bias in the acquired data. Table 1 shows the detailed demographic information of the participants.

Table 1. The demographic information of the participants

\begin{tabular}{|c|c|c|c|c|c|}
\hline \multicolumn{2}{|c|}{} & Mean & $\begin{array}{c}\text { Standard } \\
\text { Deviation }\end{array}$ & Minimum & Maximum \\
\hline \multirow{2}{*}{$\begin{array}{c}\text { Age } \\
\text { (in years) }\end{array}$} & Male & 45.63 & 16.60 & 19 & 86 \\
\cline { 2 - 6 } & Female & 45.17 & 18.48 & 19 & 90 \\
\hline
\end{tabular}

\subsection{Procedure}

After acquiring an informed consent from the participant, Computed Tomography images of their head were acquired using Siemens Somaton Scope CT scanner. The CT images were acquired in Digital Imagining and Communications in Medicine (DICOM) format files. Using Materialise MIMICS software 3D head models were developed from the CT data for all the participants as shown in Figure 1.
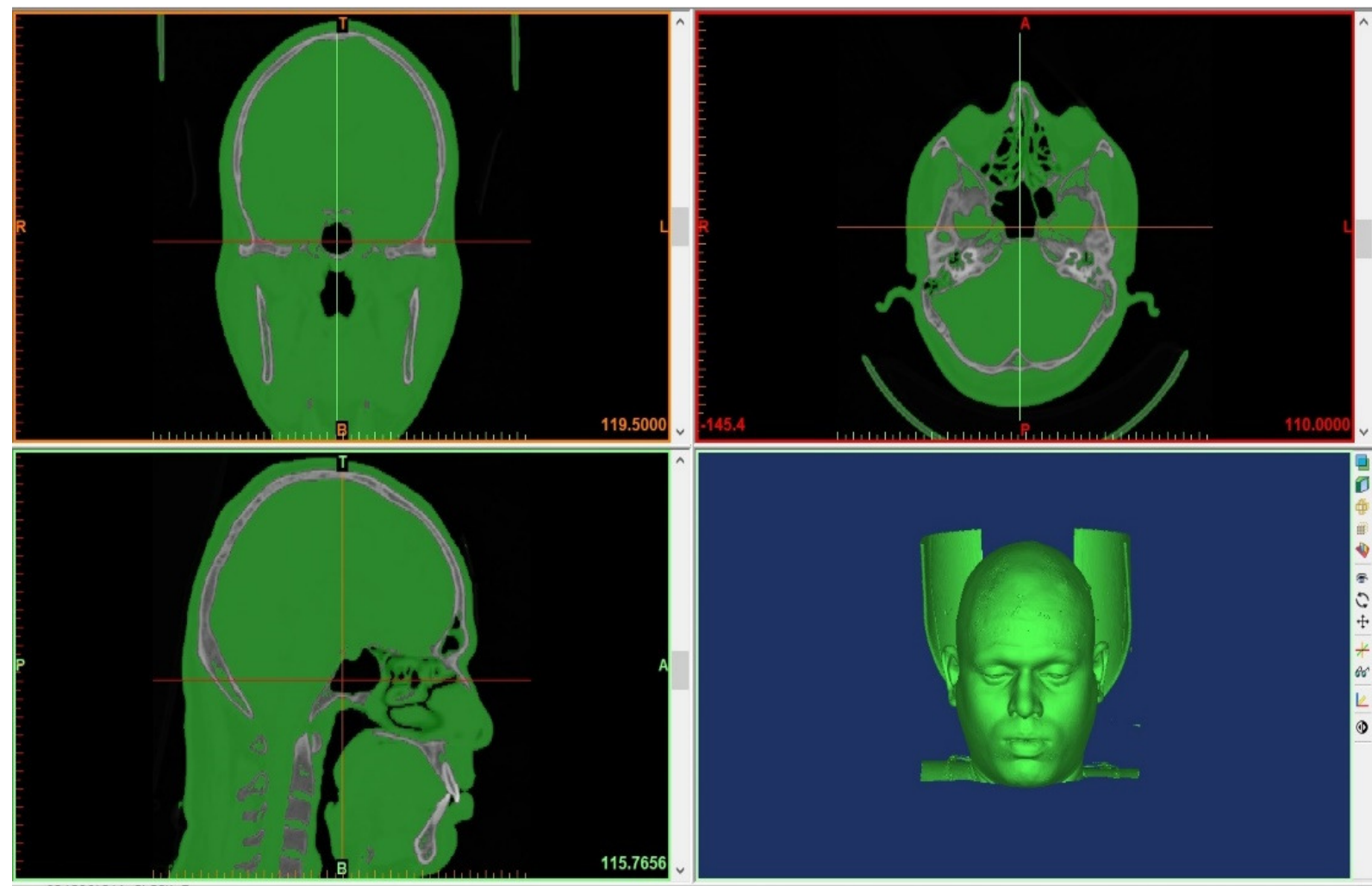

Fig. 1. Processing of CT data in Materialise Mimics

The 3D models were further cleaned and post processed to remove unwanted areas from the scan like the head mount. The individual processed 3D head model (Figure 2) was then exported in stereolithography format (.stl) files. 


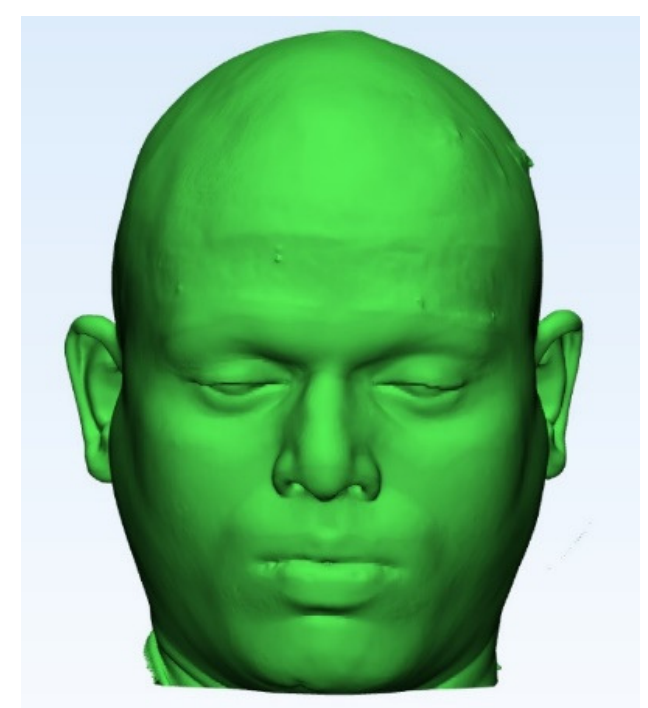

Fig. 2. Processed head model from CT data

Four key measurements were acquired including; "a"- head length, "b" head width, "c" -head circumference and "d" - anterior height of head (distance between top of the head to the naison) in Computer aided designing (CAD) software. Figure 3 shows the detailed location of the measurements.
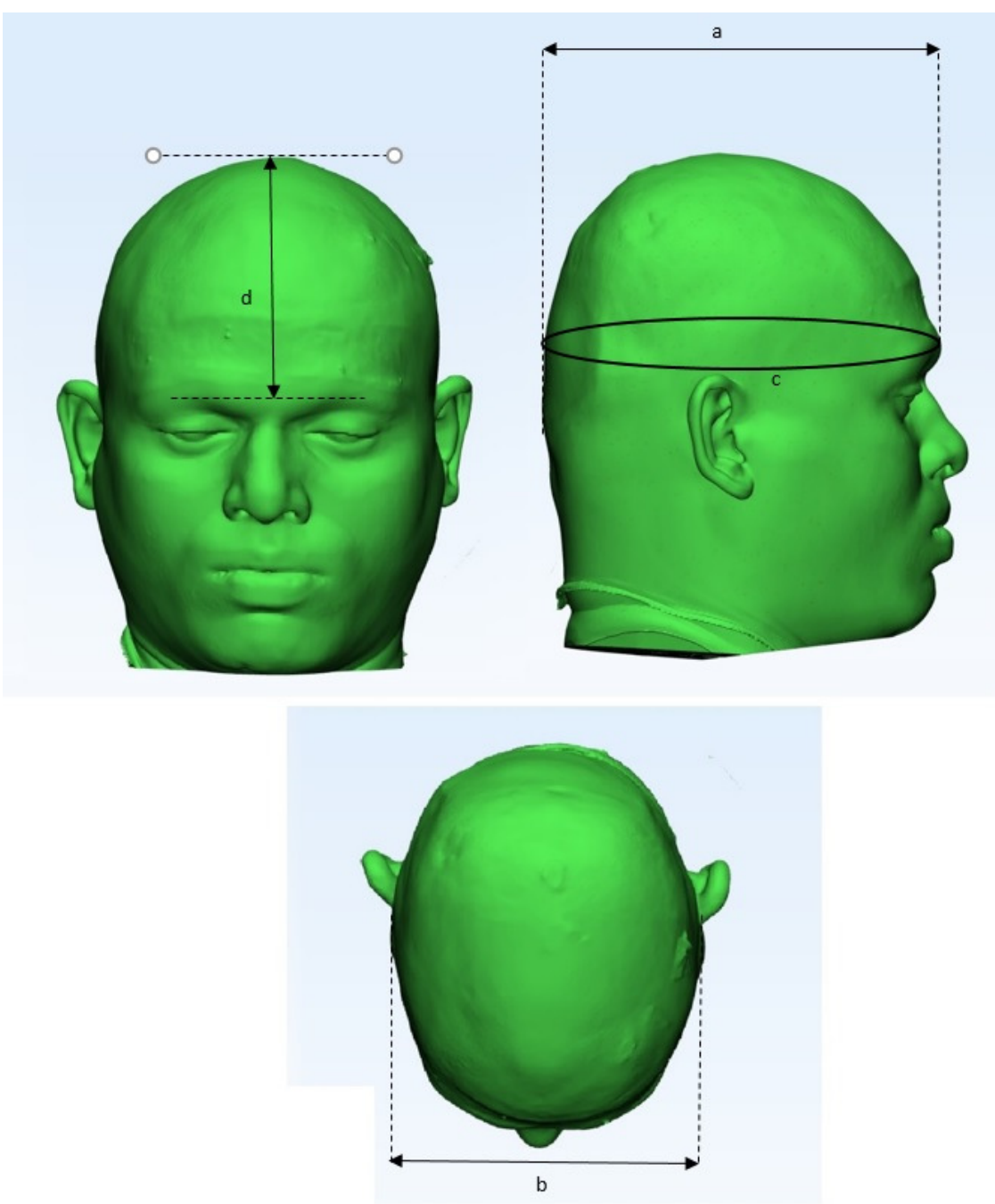

Fig. 3. Location of anthropometric measurements:

"a" - Head length, "b" - Head width, "c" - Head circumference and "d" - Anterior height of the head 


\subsection{Data Analysis}

Statistical analysis of the acquired data was performed using IBM SPSS 20.0 software. A within group descriptive statistical analysis was performed to evaluate the mean values, standard deviation and minimum and maximum values of the four anthropometric measurements. Correlation analysis were conducted to understand any relationship between the different measured dimension for both male and female.

\section{Results}

Table 2 shows a detailed descriptive statistics of the acquired data. For the current set of data, mean values of head length, width, circumference and anterior height for male participants are higher than those of females

Table 2. Descriptive Statistic of the data

\begin{tabular}{|c|c|c|c|c|c|}
\hline & & Mean & $\begin{array}{c}\text { Standard } \\
\text { Deviation }\end{array}$ & Minimum & Maximum \\
\hline $\begin{array}{c}\text { Head length } \\
\text { (in mm) }\end{array}$ & Male & 188.82 & 7.95 & 170.14 & 203.58 \\
\cline { 2 - 6 } & Female & 183.69 & 6.52 & 168.76 & 196.11 \\
\hline $\begin{array}{c}\text { Head Width } \\
\text { (in mm) }\end{array}$ & Male & 152.71 & 6.96 & 140.91 & 169.34 \\
\cline { 2 - 6 } & Female & 149.06 & 5.51 & 140.22 & 163.81 \\
\hline Head Circumference & Male & 547.66 & 16.28 & 517.14 & 578.40 \\
\cline { 2 - 6 } (in mm) & Female & 531.86 & 17.33 & 499.16 & 565.27 \\
\hline $\begin{array}{c}\text { Anterior Height } \\
\text { (in mm) }\end{array}$ & Male & 120.07 & 13.08 & 95.08 & 145.36 \\
\cline { 2 - 6 } & Female & 119.45 & 9.87 & 95.79 & 141.34 \\
\hline
\end{tabular}

Table 3 and Table 4 show the values of Pearson correlation coefficient between different parameters for the male and female participants respectively. Correlation between head length and head circumference showed a statistically significant correlation for both male and female participants. All the other parameters did not show significant correlation for both male and female participants.

Table 3. Pearson Correlation Coefficient values for different measured parameters for males ( $n=30)$

\begin{tabular}{|l|l|l|l|l|}
\hline & \multicolumn{1}{|c|}{$\begin{array}{c}\text { Head } \\
\text { length }\end{array}$} & $\begin{array}{c}\text { Head } \\
\text { width }\end{array}$ & $\begin{array}{c}\text { Head } \\
\text { circumference }\end{array}$ & $\begin{array}{c}\text { Anterior } \\
\text { height }\end{array}$ \\
\hline Head length & 1 & -0.136 & $0.672^{*}$ & 0.070 \\
\hline Head width & & 1 & 0.307 & 0.252 \\
\hline $\begin{array}{l}\text { Head } \\
\text { circumference }\end{array}$ & & & 1 & 0.200 \\
\hline $\begin{array}{l}\text { Anterior } \\
\text { height }\end{array}$ & & & & 1 \\
\hline
\end{tabular}

${ }^{*} p$ value $<0.05$

Table 4. Pearson Correlation Coefficient values for different measured parameters for females $(n=30)$

\begin{tabular}{|l|l|l|l|l|}
\hline & \multicolumn{1}{|c|}{$\begin{array}{c}\text { Head } \\
\text { length }\end{array}$} & \multicolumn{1}{|c|}{$\begin{array}{c}\text { Head } \\
\text { width }\end{array}$} & $\begin{array}{c}\text { Head } \\
\text { circumference }\end{array}$ & $\begin{array}{c}\text { Anterior } \\
\text { height }\end{array}$ \\
\hline Head length & 1 & 0.056 & $0.609^{*}$ & 0.031 \\
\hline Head width & & 1 & 0.178 & 0.010 \\
\hline $\begin{array}{l}\text { Head } \\
\text { circumference }\end{array}$ & & & 1 & 0.151 \\
\hline $\begin{array}{l}\text { Anterior } \\
\text { height }\end{array}$ & & & & 1 \\
\hline
\end{tabular}

${ }^{*} p$ value $<0.05$ 


\section{Conclusion}

The current paper presents a preliminary anthropometric investigation of four key head measurements for Indian adults. The acquired measurements include head length, width, circumference and anterior height of head, which are useful for designing head related products. The study involved sixty Indian adult participants from different age groups and their head models were acquired from computed tomography images. The required measurements were acquired using 3D CAD software. The measured values indicate that male head dimensions are larger than that of females. In addition, correlation analysis was performed to understand relationships between measured parameters, which showed significant correlation between head length and head circumference and non-significant correlations for other parameters. The sample size of the current study is small. In addition, for design of wide range of products for head, several other parameters need to be studied. In future, an extensive study needs to be conducted to create a database of head shapes of Indian adults. Such database can be useful in customizing and designing products for Indian people.

\section{Acknowledgement}

Authors would like to thank all the participants for voluntarily participating in the study. This study was supported by RGC/ECS Grant (Ref. No. F-PP2P). Authors would like to thank the staff at Asian Ergonomic Design Lab, The Hong Kong Polytechnic University and at Navneet Hi-Tech Hospital and Research Centre for the timely help and support.

\section{References}

[1] P.H. Bloch, "Seeking the ideal form: Product design and consumer response", in The Journal of Marketing, 1995, pp. 16-29, https://doi.org/10.2307/1252116

[2] P. B. Shah and Y. Luximon, "Review on 3D Scanners for Head and Face Modeling", in Digital Human Modeling. Applications in Health, Safety, Ergonomics, and Risk Management: Ergonomics and Design. DHM 2017. Lecture Notes in Computer Science, Duffy V. (eds), vol 10286. Springer, Cham, 2017, pp. 47-56, https://doi.org/10.1007/978-3-319-58463-8_5

[3] Y. Luximon and P. Shah, "Effect of the accuracy of 3D head scanners in product design development", in The Japanese Journal of Ergonomics, 53(Supplement2), 2017, pp. S372-S375, https://doi.org/10.5100/jje.53.S372

[4] Z. Fourie et al., "Evaluation of anthropometric accuracy and reliability using different three-dimensional scanning systems", in Forensic Science International, 207(1-3), 2011, pp. 127-134, https://doi.org/10.1016/j.forsciint.2010.09.018

[5] M. Kouchi and M. Mochimaru, "Errors in landmarking and the evaluation of the accuracy of traditional and 3D anthropometry", in Applied ergonomics, 42(3), 2011, pp. 518-527, https://doi.org/10.1016/j.apergo.2010.09.011

[6] J. Xia et al, "Computer-assisted three-dimensional surgical planning and simulation: 3D virtual osteotomy", in International journal of oral and maxillofacial surgery, 29(1), 2000, pp. 11-17, https://doi.org/10.1016/S0901-5027(00)80116-2

[7] T. J. Horgan and M. D. Gilchrist, "The creation of three-dimensional finite element models for simulating head impact biomechanics", in International Journal of Crashworthiness, 8(4), 2003, pp. 353-366, https://doi.org/10.1533/ijcr.2003.0243

[8] D. Lacko et al., "Evaluation of an anthropometric shape model of the human scalp", in Applied ergonomics, 48, 2015, pp. 70-85, https://doi.org/10.1016/j.apergo.2014.11.008

[9] Y. Chen and M. Ostoja-Starzewski, "MRI-based finite element modeling of head trauma: spherically focusing shear waves", in Acta Mechanica, 213(1-2), 2010, pp. 155-167. https://doi.org/10.1007/s00707-009-0274-0

[10]J. M. Plooij et al., "Evaluation of reproducibility and reliability of 3D soft tissue analysis using 3D stereophotogrammetry", in International journal of oral and maxillofacial surgery, 38(3), 2009, pp. 267-273, https://doi.org/10.1016/j.ijom.2008.12.009

[11]T. C. Hsung et al., "Recording of natural head position using stereophotogrammetry: a new technique and reliability study", in Journal of Oral and Maxillofacial Surgery, 72(11), 2014, pp. 2256-2261, https://doi.org/10.1016/j.joms.2014.03.025

[12]Y. Luximon et al., "The 3D Chinese head and face modeling", in Computer-Aided Design, 44(1), 2012, pp. 40-47, https://doi.org/10.1016/j.cad.2011.01.011

[13]L. Kovacs et al., "Three-dimensional recording of the human face with a 3D laser scanner", in Journal of plastic, reconstructive \& aesthetic surgery, 59(11), 2006, pp. 1193-1202. https://doi.org/10.1016/j.bjps.2005.10.025 
[14]P. Shah and Y. Luximon, "Three-dimensional human head modelling: a systematic review", in Theoretical Issues in Ergonomics Science, 2018. DOI: 10.1080/1463922X.2018.1432715Y.

[15] K.M. Robinette et al., "The CAESAR project: a 3-D surface anthropometry survey". in Proc. of Second International Conference on 3-D Digital Imaging and Modeling, Ontario, Canada,1999, pp. 380-386, https://doi.org /10.1109/IM.1999.805368

[16]T. Perret-Ellena et al, "3D Anthropometric investigation of Head and Face characteristics of Australian Cyclists", in Procedia Engineering, 112, 2015, pp. 98-103, https://doi.org/10.1016/j.proeng.2015.07.182

[17]H.P. Lee et al., "Development of an Anthropometric Database Representing the Singapore Population", in Proc. of 6th International Conference on 3D Body Scanning Technologies, Lugano, Switzerland, 2015, pp. 27-28, http://dx.doi.org/10.15221/15.234

[18]H. S. Baik et al., "Facial soft-tissue analysis of Korean adults with normal occlusion using a 3-dimensional laser scanner", in American journal of orthodontics and dentofacial orthopedics, 131(6), 2007, pp. 759-766, https://doi.org/10.1016/j.ajodo.2005.08.038

[19]D.S. Ma et al., "The Chicago face database: A free stimulus set of faces and norming data", in Behavior research methods, 47(4), 2015, pp. 1122-1135. https://doi.org/10.3758/s13428-014-0532-5

[20]L. Talbert et al., "A 3D analysis of Caucasian and African American facial morphologies in a US population", in Journal of orthodontics, 41(1), 2014, pp.19-29. https://doi.org/10.1179/1465313313Y.0000000077

[21]R. Ball et al., "A comparison between Chinese and Caucasian head shapes", in Applied Ergonomics, 41, no. 6, 2010, pp. 832-839. https://doi.org/10.1016/j.apergo.2010.02.002 